\title{
Composite tissue allotransplantation of the face: Decision analysis model
}

\author{
Sabrina Cugno MSc MD ${ }^{1}$, Sheila Sprague MSc ${ }^{2}$, Eric Duku MSc P Stat ${ }^{4}$, Achilleas Thoma MD MSc FRCSC FACS $1,2,3$
}

S Cugno, S Sprague, E Duku, A Thoma. Composite tissue allotransplantation of the face: Decision analysis model. Can J Plast Surg 2007;15(3):145-152.

BACKGROUND: Facial composite tissue allotransplantation is a potential reconstructive option for severe facial disfigurement. The purpose of the present investigation was to use decision analysis modelling to ascertain the expected quality-adjusted life years (QALYs) gained with face transplantation (versus remaining in a disfigured state) in an effort to assist surgeons with the decision of whether to adopt this procedure.

STUDY DESIGN: The probabilities of potential complications associated with facial allotransplantation were identified by a comprehensive review of kidney and hand transplant literature. A decision analysis tree illustrating possible health states for face allotransplantation was then constructed. Utilities were obtained from 30 participants, using the standard gamble and time trade-off measures. The utilities were then translated into QALYs, and the expected QALYs gained with transplantation were computed.

RESULTS: Severe facial deformity was associated with an average of 7.34 QALYs. Allotransplantation of the face imparted an expected gain in QALYs of between 16.2 and 27.3 years.

CONCLUSIONS: The current debate within the medical community surrounding facial composite tissue allotransplantation has centred on the issue of inducing a state of immunocompromise in a physically healthy individual for a non-life-saving procedure. However, the latter must be weighed against the potential social and psychological benefits that transplantation would confer. As demonstrated by a gain of 26.9 QALYs, participants' valuation of quality of life is notably greater for face transplantation with its side effects of immunosuppression than for a state of uncompromised physical health with severe facial disfigurement.

\section{Une allotransplantation de tissus composites de la face : Un modèle d'analyse décisionnelle}

HISTORIQUE : L'allotransplantation des tissus composites de la face est
une possibilité de reconstruction en cas de grave défigurement. La
présente exploration visait à utiliser un modèle d'analyse décisionnelle
afin de déterminer les années de vie pondérées par la qualité (AVPQ)
prévues obtenues par une greffe du visage (par rapport au fait de demeu-
rer défiguré) pour aider les chirurgiens à décider ou non d'adopter cette
intervention. CONCEPTION DE L'ÉTUDE : Une analyse approfondie des publications sur les greffes du rein et de la main a permis de repérer les probabilités de complications potentielles associées à une allotransplantation faciale. On a ensuite construit un arbre d'analyse décisionnelle pour illustrer les états de santé possibles reliés à l'allotransplantation de la face. On a obtenu les valeurs utilitaires auprès de 30 participants, au moyen des mesures de hasard-type standard et de marchandage-temps. Les valeurs utilitaires ont ensuite été converties en AVPQ, et on a calculé les AVPQ qu'on prévoyait obtenir grâce à la greffe.

RÉSULTATS : Les graves malformations faciales s'associent à une moyenne de 7,34 AVPQ. L'allotransplantation de la face ajoutait un gain prévu d'AVPQ de 16,2 à 27,3 années.

CONCLUSIONS : La controverse actuelle au sein du corps médical entourant l'allotransplantation de tissus composites de la face est axée sur l'induction d'un état d'immunodéficience chez une personne en bonne santé en raison d'une intervention non salvatrice. Cependant, il faut pondérer cette constatation par rapport aux bienfaits sociaux et psychologiques potentiels de la greffe. Comme le démontre un gain de 26,9 AVPQ, l'évaluation que font les patients de la qualité de vie est considérablement plus élevée à l'égard d'une greffe de la face, avec ses effets secondaires d'immunodéficience, qu'un état de santé physique non compromis accompagné d'un important défigurement.

Key Words: Decision analysis; Facial transplantation; Qualityadjusted life years

he practice of composite tissue allotransplantation (CTA)
in reconstructive surgery was introduced with the hand allograft in September 1998 (1), and has since had success with other anatomical components, including the larynx, abdominal wall and knee joint (2). Early results of the first clinical cases have demonstrated partial functional recovery with evidence of cortical integration of the anatomical part, while prevention of graft rejection in the absence of major or irreversible complications was achieved with immunosuppressive treatment $(1,3-12)$.

Although in its infancy, CTA extends the boundaries of reconstructive surgery to patients with tissue defects for which acceptable reconstruction with autologous tissue is limited. Management of severe facial disfigurement best exemplifies this problem. Outcome with conventional reconstructive techniques, including skin grafts, local flaps, tissue expansion and free tissue transfers, as well as skin substitute, is rarely considered satisfactory with regard to both function and cosmesis (13). However, as demonstrated by the success reported for two cases of total face and scalp replantation for traumatic defects, these objectives can, in theory, be achieved with reconstruction using facial skin $(14,15)$. This should not be surprising, because it is in keeping with the pre-eminent objective of reconstructive surgery, which is to replace like with like. The

\footnotetext{
${ }^{1}$ Surgical Outcomes Research Centre (SOURCE), McMaster University; ${ }^{2}$ Department of Surgery, Division of Plastic and Reconstructive Surgery, St Joseph's Healthcare; ${ }^{3}$ Department of Clinical Epidemiology and Biostatistics; ${ }^{4}$ Department of Psychiatry and Behavioural Neurosciences, McMaster University, Hamilton, Ontario

Correspondence: Dr Achilleas Thoma, 206 James Street South, Suite \#101, Hamilton, Ontario L8P 3A9. Telephone 905-523-0019,

fax 905-523-0229, e-mail athoma@mcmaster.ca
} 


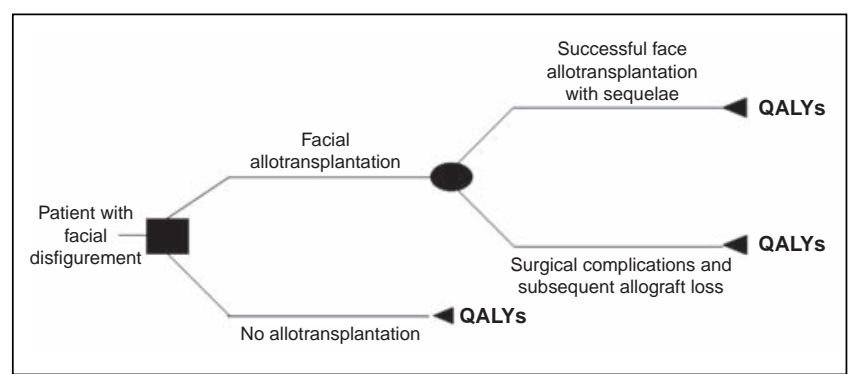

Figure 1) Decision analysis tree illustrating possible health states (pathways) for facial disfigurement. QALYs Quality-adjusted life years

latter, in combination with the ostensive success of hand transplantation (16), has led to the advance of facial CTA as a potential reconstructive option for severe facial disfigurement in humans $(10,17-19)$. A French team, led by Dr JeanMichel Dubernard, performed the first partial face transplant in 2005 on a 38-year-old woman who had suffered extensive injuries from a dog attack (20). In April 2006, the Xijing military hospital in Xian, China, carried out a similar operation, transplanting the cheek, upper lip and nose of a hunter who was mauled by a bear (21).

Although the face allograft is conceptually the consummate reconstructive alternative for facial defects, with no donor site morbidity, the prospect of facial allotransplantation has provoked great debate within the medical community $(22,23)$. The discussion has primarily centred on the issue of the inherent risk associated with indefinite immunosuppressive treatment for a non-life-saving procedure in an otherwise physically uncompromised patient $(10,24,25)$. Additional concerns are the absence of long-term data on CTAs performed to date (with particular emphasis on chronic rejection) (26), the feasibility of achieving adequate functional recovery of the graft, the limited suitable donors for cosmetic matching between donor and recipient, as well as the psychological repercussions associated with the acquisition of a new face. However, these issues must be weighed against the potential social and psychological benefits that transplantation would confer to candidate patients $(27,28)$.

In absence of clinical data, decision analysis modelling can be used to determine whether CTA of the face should be pursued as a potential solution for a selected group of patients with facial deformities that cannot be adequately addressed with conventional reconstructive procedures. Decision analysis, rooted in health economics, is a set of explicit, quantitative methods used for the comparison of the expected consequences or outcomes of pursuing different strategies (eg, facial CTA versus severe facial disfigurement) (29). The preference for or desirability of each health outcome, termed utility, can be ascertained and transformed into quality-adjusted life years (QALYs). The QALY was developed as an attempt to integrate length of life (or time spent in a particular health state) and quality of life (in that state) into a single index measure (29). The QALYs associated with each health state can be fitted into a decision tree, and the number of QALYs gained from the procedure (in this case, face allotransplantation) can be determined.

The decision to perform any surgical intervention, such as facial CTA, should be based on the principle of 'primum non nocere', despite a lack of satisfactory outcomes with alternate procedures. Although this is the responsibility of the surgeon, who as a result is ultimately charged with the decision of whether to perform face transplantation, it is only the recipient who can justify the risks of this procedure for the expected benefits. Thus, the purpose of the present investigation was to use decision analysis modelling to ascertain the expected QALYs gained with face transplantation in an effort to assist surgeons with the decision of whether to adopt CTA of the face.

\section{METHODS}

\section{Treatment strategies}

A decision analysis tree was constructed (Figure 1) illustrating possible health states (pathways) for facial disfigurement. The two clinical strategies (decision node) were remaining with severe facial deformity or undergoing face allotransplantation. Stage 1 of this model, representing the immediate postoperative period in the case of transplantation, was defined as two weeks based on the assumption that complications associated with immunosuppression would not occur before this twoweek period (16). Stage 2, representing all possible health states following face CTA, was conservatively defined as the rest of the recipient's life.

Based on experience from previous CTA procedures (30-33), namely, hand allotransplants, it was assumed that the maintenance immunosuppressive regimen implemented for a face transplant would include a combination of tacrolimus (adjusted blood concentration of $5 \mathrm{ng} / \mathrm{mL}$ to $10 \mathrm{ng} / \mathrm{mL}$ ), mycophenolate mofetil $(500 \mathrm{mg} /$ day to $3000 \mathrm{mg} /$ day $)$ and prednisone ( $2.5 \mathrm{mg} /$ day to $30 \mathrm{mg} /$ day) $(5,10,11,16,34,35)$.

\section{Face allotransplantation}

The decision tree outlined two possible events (chance node) that may occur following CTA of the face. These events included successful face transplantation, which was defined as a successful surgical result, and surgical complications, with subsequent flap failure. Although studies report successful surgical outcome following replantation of the avulsed face $(14,15)$, facial transplantation does not have the experience that hand allotransplantation has from decades of limb replantation. Thus, the sequelae of technical failure must be specifically emphasized. However, given the extensive success of free tissue transfer for head and neck reconstruction, the surgical outcome for the facial flap can be anticipated to parallel these results. Thus, the probability of microsurgical complications and flap failure (ie, probability of successful face allotransplantation) was estimated from head and neck free flap literature $(17,22)$.

\section{Treatment outcomes}

In an effort to identify the clinically important complications that may be associated with allotransplantation of the face (outcome node), the literature on CTAs and kidney allografts was analyzed (36). The literature search utilized MEDLINE and EMBASE electronic databases, and was limited to human subjects and the English language. The search included articles published between 1996 and November 2005. Inclusion criteria were restricted to reports based on:

- transplants with the maintenance immunosuppressive regimen anticipated for face allotransplantation;

- recipients of renal transplants (cadaveric or living donor) who had not undergone other organ transplantation;

- a minimum of six months of follow-up and 50 patients; and 


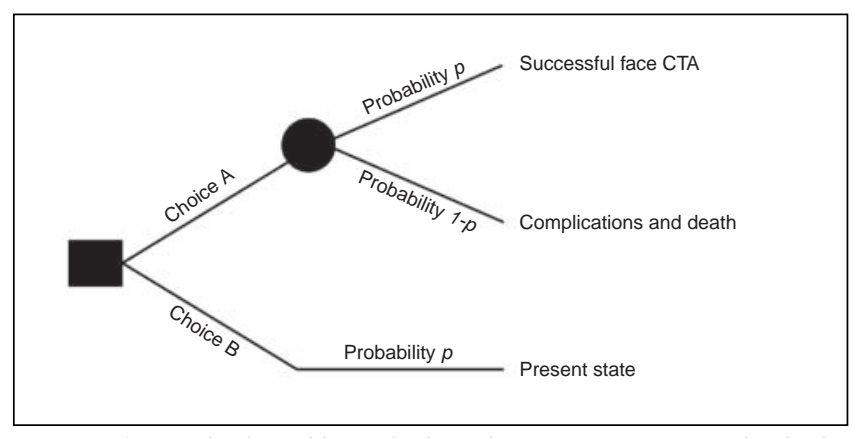

Figure 2) Standard gamble method for the measurement of individuals' preferences under uncertainty. CTA Composite tissue allotransplantation

- data on three or more of the following outcomes - graft loss, death, incidence of acute rejection and incidence of post-transplant diabetes mellitus.

If data were available, allograft losses due to death were excluded in the calculation of graft loss, in view of the observation that death in a patient with a functioning allograft is usually related to associated morbidity (such as cardiovascular disease), which may have been present before transplantation (37), and based on the presumption that candidate recipients for face allografts have minimal pre-existing comorbidities.

Reports on registry data, including recently published reports on the International Registry of Hand Composite Tissue Transplantation $(16,38)$, were excluded to obviate the repeated inclusion of results from the same patient. Further, studies that examined high-risk transplant recipients (eg, elderly patients, patients with previous allograft failures), the pediatric population, patients with delayed graft function or recipients of grafts from non-heart-beating donors as the main study population were also excluded. Many recent studies have investigated outcomes following complete withdrawal of corticosteroids from standard immunosuppressive regimens. However, in light of the fact that all but two maintenance protocols for the hand allografts performed to date involved steroid therapy (16), if a protocol-defined goal of a study was the discontinuation of corticosteroids, it was excluded from the analysis.

Data were extracted from the relevant publications and summarized to include the number of patients involved and the particular complications associated with the transplants. Although a myriad of complications are theoretically possible following allotransplantation, the complications included in the model comprised the most common complications noted among hand transplant recipients, as well as complications deemed clinically important and probable given the experience with solid organ allotransplants and the anticipated immunosuppressive regimen.

Hand allograft offers the most analogous model for a face CTA; however, to date, the number of hand transplantations is small, and long-term data are not yet available. For this reason, solid organ transplantations, for which there are abundant and more extensive data, were also reviewed. The latter consisted of kidney transplants, in view of the fact that the immunosuppressive protocol used for hand allotransplantation is based on, and hence most comparable with, that implemented for kidney transplantation. It was therefore hypothesized that the risk of immunosuppression associated with a facial composite tissue transplant would be similar to that of a kidney transplant (36).

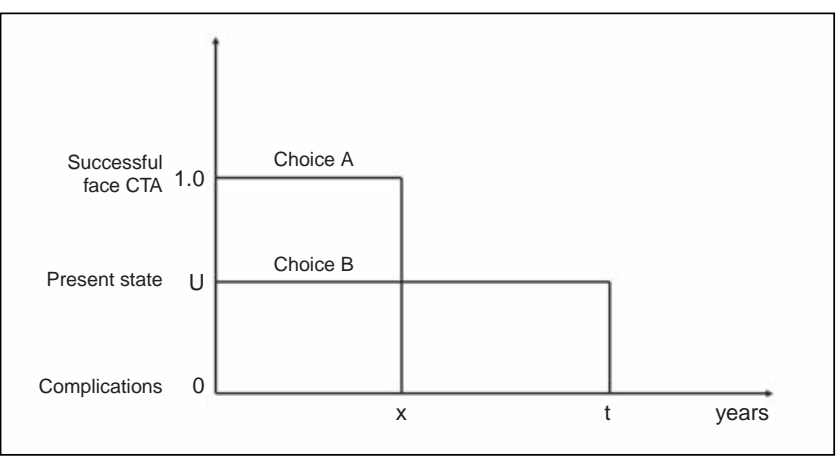

Figure 3) Time trade-off method for the measurement of individuals' preferences under uncertainty. CTA Composite tissue allotransplantation; $t$ Given life expectancy; $x$ Shortened life expectancy

The only exception was analysis of heart transplant data for estimation of the probability of hypertension and nephrotoxicity.

Because there are various pathways that can occur if a complication arises with the allograft or chronic immunosuppression, certain assumptions were made. For instance, irreversible complications associated with the surgical procedure, such as flap failure, would necessitate debridement of the allograft and skin grafting of the facial defect. Furthermore, the assumption of mutually exclusive health states was made, and based on experience with hand transplants, it was also presumed that the majority of complications attributed to immunosuppressive therapy could be reversed with dose adjustments.

\section{Utility estimates and QALYs}

Utilities of the various health outcomes associated with CTA of the face and severe disfigurement were obtained from a sample of convenience consisting of 30 medical students. Each participant was presented with a photograph of an individual with facial trauma severe enough to warrant a face transplant and was then given a scenario such as: "You are 30 years of age and have sustained a burn to the face, which has resulted in severe deformity, similar to the individual pictured in this photograph. The only treatment that can restore the appearance of a normal face is a facial transplant. However, transplantation requires that you remain on drugs for the rest of your life in order to prevent losing your face. Unfortunately, these drugs have serious side effects, for example, diabetes." Because the clinical course following face transplantation was anticipated to approximate the experience with hand allografts, when possible, subsequent description of clinical scenarios associated with each health state reflected the clinical manifestation of that particular complication in patients with CTAs.

Utilities were computed from values obtained with the standard gamble and time trade-off methods (29). The standard gamble presented participants with choices A and B. Choice A consisted of varying probabilities of successful face transplantation (defined as successful surgery and no subsequent complications) and associated complications (including death), and choice $B$ represented severe facial disfigurement (Figure 2).

With the time trade-off, participants were also presented with two choices: choice A, with a shortened life expectancy of $x$ years, and choice $B$, with a given life expectancy of $t$ years (Figure 3). In other words, patients were asked about how much of their life expectancy they would be willing to trade off to avoid the health state denoted by choice B (for example, 
facial disfigurement). The value of the shortened life expectancy (ie, $x$ years in choice A) was varied until the participant was indifferent with respect to the two alternatives. At that point, the utility value of the health state in question was estimated by the proportion between the shortened life expectancy $x$ and the full life expectancy of the intermediate outcome t. In both utility measures, utility of a particular health state was simply the probability of successful facial transplantation at the indifference point (ie, when choices A and $\mathrm{B}$ were considered equal). The greater chance of complications that a participant was willing to accept in choice $A$, the worse the utility of the health state in choice B.

QALYs for face transplantation and severe facial deformity were then derived from the utility values obtained. The calculation of QALYs was based on the following general assumptions: a hypothetical patient is 30 years of age and has a total life expectancy of 76.8 years (based on the general American population), and health states associated with face CTA would persist for the remainder of the patient's life (ie, 46.8 years). For instance, the QALY calculation for post-transplant diabetes mellitus, which has a utility of 0.83 (with the standard gamble), was as follows:

QALY $=$ duration of health state $\times$ utility of health state

+ (number of healthy years remaining - duration of

health state) $\times$ utility of successful face transplantation

$$
\mathrm{QALY}=46.8 \times 0.83+(46.8-46.8) \times 0.86
$$

$$
\mathrm{QALY}=38.8
$$

Utilities, expressed as QALYs, as well as the probabilities associated with each of these health states, were fitted into the decision analysis model. The expected QALYs were then computed. The probabilities of each health state, as determined from the literature, were first modified such that the probabilities resulting from a chance node added up to 1.0, providing the adjusted probability. The expected QALYs associated with each health state were calculated by multiplying the QALYs of the health state in question by the adjusted probability of that health state and finally by the probability of successful face transplantation. The effectiveness of facial transplantation was measured in expected QALYs gained with this procedure compared with a state of severe facial deformity. The QALYs gained is simply the expected QALYs for face CTA (ie, the sum of the expected QALYs for each possible health outcome associated with this procedure, as outlined in the model) minus the expected QALYs for no transplantation.

\section{Sensitivity analysis}

Sensitivity analysis was performed to determine whether the conclusions were robust, because it is reasonable to presume that a face transplant recipient would not attain the life span expected for a member of the general population (ie, 46.8 years) in view of the requisite immunosuppressive therapy. This was confirmed through the evaluation of the worst case scenario, which was based on the presumption that the life expectancy of a face transplant recipient would be equivalent to a kidney transplant patient aged 30 years (ie, 58.5 years, based on the United States Renal Data System) (39) rather than that of the general population.

\section{RESULTS}

The search strategy identified 892 articles, of which 543 were considered to be potentially relevant. This number was further decreased to 109 articles, which were reviewed in full. Twenty-nine articles fulfilled the criteria outlined above and were included for analysis. It should be noted that in an effort to avoid double-counting, data from several seemingly relevant articles were not included in the analysis because this would have resulted in a biased probability estimate. The probabilities of the most common and clinically important complications potentially associated with face allotransplantation based on kidney and hand transplant literature are listed in Table 1 $(1,4,5,7-9,11,12,40-60)$.

The sample of 30 volunteers ( 18 women) surveyed had a mean \pm SD age of $33 \pm 4.3$ years. Participants were medical students at McMaster University, Hamilton, Ontario. Utilities and QALYs for each health state were obtained from the participants with the standard gamble and time trade-off. The decision analysis tree for face allotransplantation, including adjusted probabilities and QALYs for each health state (pathway), is illustrated in Figure 4.

Severe facial deformity was associated with 9.36 and 8.9 QALYs, as computed with the standard gamble and time trade-off, respectively. The expected QALYs gained with facial CTA were estimated as 27.3 and 26.5 years, with the above listed measures. The QALYs calculated for facial disfigurement in the sensitivity analyses (based on the life expectancy of a kidney transplant patient 30 years of age) were 5.7 and 5.4 , as derived from utilities measured with standard gamble and time trade-off, respectively. Furthermore, allotransplantation of the face imparted an expected gain of 16.6 and 16.2 QALYs, respectively. Thus, face CTA confers between 16.2 and 27.3 years of perfect health to individuals with severe facial deformity.

\section{DISCUSSION}

The short-term success attained with hand and other CTAs has led to the application of CTA for patients with facial defects not amenable to reconstruction with autologous tissues. Allotransplantation necessitates permanent immunosuppressive therapy, which is deemed justified in solid organ transplants in view of the provision of life or alleviation of chronic disease that such transplantation confers. However, the inherent risk associated with indefinite immunosuppression is heralded by opponents of CTA as unreasonable for a non-life-saving procedure in an otherwise physically healthy individual. An additional and chief concern of CTA is the absence of long-term data on composite tissue transplants performed to date. However, the latter must be weighed against the potential social and psychological benefits that transplantation would provide candidate recipients. In fact, as demonstrated by a utility of 0.2 for extreme facial deformity, as well as an expected gain of between 16.2 and 27.3 QALYs, the general public's valuation of quality of life is notably greater for face transplantation and the side effects of immunosuppression than for a state of uncompromised physical health with severe facial disfigurement. For purposes of comparison, kidney transplantation has been associated with a utility value of 0.94 , while the utilities of breast hypertrophy and moderate angina have been estimated as 0.76 and 0.90 , respectively (61). The reported gain in QALYs with allotransplantation can be interpreted to mean 
TABLE 1

Probability of complications potentially associated with face transplantation as derived from the literature

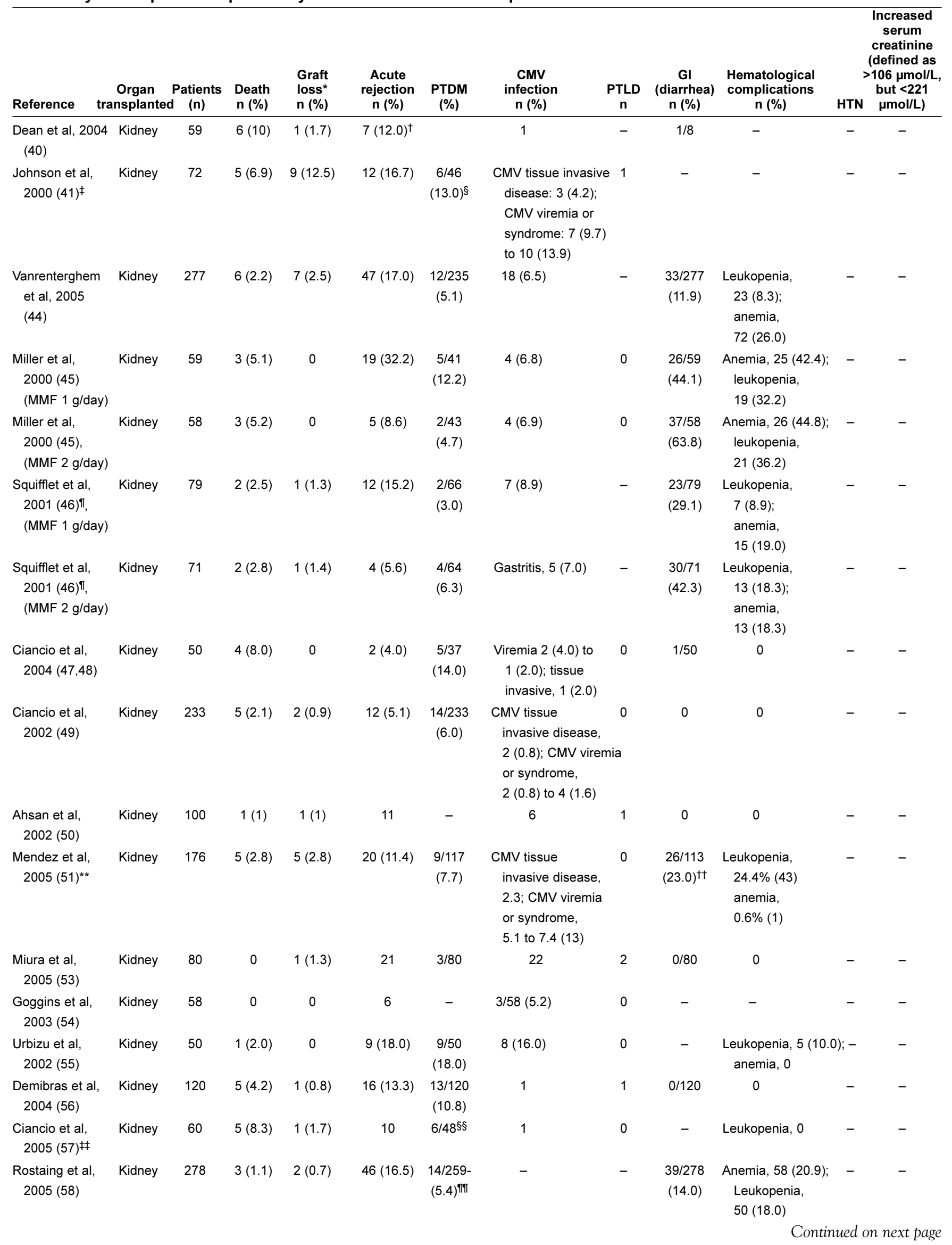


TABLE 1 - continued

Probability of complications potentially associated with face transplantation as derived from the literature

\begin{tabular}{|c|c|c|c|c|c|c|c|c|c|c|c|c|}
\hline Reference & $\begin{array}{c}\text { Organ } \\
\text { ransplanted }\end{array}$ & $\begin{array}{l}\text { Patients } \\
\text { d (n) }\end{array}$ & $\begin{array}{l}\text { Death } \\
\text { n (\%) }\end{array}$ & $\begin{array}{l}\text { Graft } \\
\text { loss* } \\
\text { n (\%) }\end{array}$ & $\begin{array}{l}\text { Acute } \\
\text { rejection } \\
\text { n (\%) }\end{array}$ & $\begin{array}{l}\text { PTDM } \\
\text { (\%) }\end{array}$ & $\begin{array}{c}\text { CMV } \\
\text { infection } \\
n(\%)\end{array}$ & $\begin{array}{c}\text { PTLD } \\
\mathbf{n}\end{array}$ & $\begin{array}{c}\text { GI } \\
\text { (diarrhea) } \\
\mathrm{n}(\%)\end{array}$ & $\begin{array}{c}\text { Hematological } \\
\text { complications } \\
n(\%)\end{array}$ & HTN & $\begin{array}{c}\text { Increased } \\
\text { serum } \\
\text { creatinine } \\
\text { (defined as } \\
106 \mu \mathrm{mol} / \mathrm{L}, \\
\text { but }<221 \\
\mu \mathrm{mol} / \mathrm{L} \text { ) }\end{array}$ \\
\hline $\begin{array}{r}\text { Hand transplants } \\
(1,4,5,7-9,11,12\end{array}$ & $\begin{array}{l}\text { ts Hand } \\
12 \text { ) }\end{array}$ & 10 & 0 & 1 & 8 & $6 / 9$ & 5 & 0 & $0 / 10$ & 6 - anemia & 2 & 6 \\
\hline \multirow[t]{2}{*}{$\begin{array}{l}\text { Taylor et al, } \\
2005(59)^{\star * *}\end{array}$} & Heart & 5668 & - & - & - & - & - & - & - & - & $\begin{array}{c}76.8 \\
(4353)\end{array}$ & - \\
\hline & & 5727 & & & & & & & & & & $\begin{array}{c}22.1 \\
(1266)\end{array}$ \\
\hline
\end{tabular}

*Where possible, graft loss secondary to rejection was included exclusively; ${ }^{\dagger}$ Clinical acute rejection; IIncludes data from Ashan et al, 2001 (42), and Gonwa et al, 2003 (43) for 2- and 3-year follow-up data, respectively; \$Plus, 2/46 (5.9) who required oral hypoglycemic agent; TAcute rejection as determined clinically - or biopsy proven; **Includes 6-month follow-up data from Gonwa et al, 2003; t†Mycophenolate mofetil (MMF) discontinuation, 21.1 (4/19), and MMF dose adjustments, 23.3 (22/94); ${ }^{\prime}$ Post-transplant diabetes mellitis (PTDM) was defined as insulin or oral hypoglycemic agent; \$§Three additional patients required oral hypoglycemic agents (total, 9/48); TाiHyperglycemia reported in 44 (15.8) patients; ${ }^{* * *}$ Cumulative prevalence of post-transplant morbidity in survivors within 1 year for transplants performed between January 2000 and June 2003. Results from the Registry of International Society for Heart and Lung Transplantation (59) was used as primary heart transplantation studies, which utilize tacrolimus, MMF and steroids as maintenance immunosuppressive therapy, either do not report on these parameters, withdraw steroids after an initial induction period, or outline the mean blood pressure and serum creatinine, and thus do not indicate the incidence of these complications. If only incidence or percentage of patients with given complications given as part of list of reasons for discontinuation of therapy, then that number is included/indicated. Where possible, graft loss secondary to chronic rejection reported only. CMV Cytomegalovirus; Gl Gastrointestinal; HTN Hypertension; PTLD Post-transplant lymphoproliferative disease

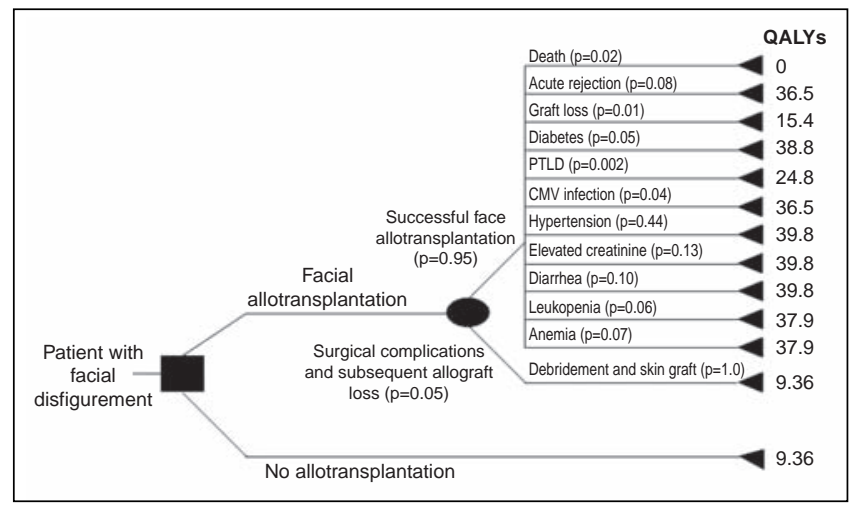

Figure 4) Decision analysis tree for composite tissue allotransplantation of the face, including adjusted probabilities and quality-adjusted life years for each health state (pathway). The probabilities of each health state, as determined from the literature (Table 1), were first modified such that the probabilities resulting from a chance node add up to 1.0, providing the adjusted probability. CMV Cytomegalovirus; PTLD Post-transplant lymphoproliferative disease; QALYs Quality-adjusted life years

that face CTA confers approximately 21.8 years of perfect health to recipients, given the assumption that the recipient of a face allograft would have an average life expectancy and, in extension, a gain in QALYs that approximates that between a healthy individual and a kidney transplant patient.

A decision analysis model was used for estimation of the expected gain in QALYs with face CTA. However, several limitations of this model must be particularly emphasized. First, the assumption of mutually exclusive health states was made for pragmatic reasons in an effort to simplify the model. However, this presumption does not accurately reflect the fact that a CTA recipient would likely experience more than one of the complications outlined. For instance, an acute rejection episode necessitating immunosuppression dose adjustments may precipitate transient hyperglycemia or increased serum creatinine levels (5). A second limitation of this simplistic model is that the complications considered are nonexhaustive (eg, graft-versus-host disease), and their probabilities are based on short-term data despite efforts to obviate the exclusion of long-term data by review of reports on solid organ transplants. The latter also advances the methodological limitation of comparing probabilities of immunosuppression-induced complications from divergent allotransplants, given that physical health has considerable implications for drug tolerability, and recipients of kidney allografts have higher pre-existing morbidity relative to potential CTA recipients. In addition, kidney transplant patients suffer from at least some of the symptoms of uremia, such that not all the neurological, hematological or gastrointestinal symptomatology may be attributed to immunosuppressive therapy. Thus, the data utilized for computation must be considered approximations and most likely present the upper limits of potential risks in face transplantation (36). Third, the duration of each complication was defined as the remainder of the recipient's life (ie, stage 2 as 46.8 years), despite the fact that the occurrence of certain immunosuppression-induced states are maximal within the first year following transplantation. This time period was selected to account for the continuous risk of recurrence of particular health states as well as to reflect the unpredictable clinical course following a face transplant. Alternatively, a Markov model could have been implemented (29). This model proceeds by determining transition probabilities between different health states, and characterizes branches at particular time points when recurrence would be evaluated. However, this model necessitates a large decision tree, the complexity of which was deemed beyond the scope of an initial analysis. Such a model can be considered in the future when clinical data from actual face transplants become available. Finally, 
there is general agreement that patients or members of the general population are preferred to experts for measurement of utility values (29). For practical reasons, we chose medical students, because it made it easier to explain the health states and they were a convenient sample. In the future, we intend to test this model in a sample of disfigured patients, such as burn victims.

Given the implications of chronic rejection, this issue must be specifically addressed. As previously mentioned, chronic rejection and consequent impairment of functional capacity has been cited as a cardinal reason against implementation of facial transplantation. This phenomenon, well documented in solid organ allografts (37), presents critical potential long-term sequelae of CTA of the face in view of the young age anticipated for recipients, the marked antigenicity of skin and the formidable effects of allograft debridement. Because long-term data on CTAs are scant, the probability of chronic rejection of the face allograft was based almost exclusively on data from kidney transplants. Some authors have suggested that chronic rejection of CTAs can be estimated as the half-life of solid organ transplants. The half-life of a kidney transplant on tacrolimus-led therapy, for instance, is approximately 14 years (62). Should chronic rejection of the face allograft definitely ensue within this period, then the decision analysis model proposed, as well as the computed gain in QALYs, would likely be affected. This was not considered in the design of the model and we remain fully cognizant of this potential study limitation. However, the ability to induce allograft tolerance in CTA recipients, an area of active research, would mitigate the

\section{REFERENCES}

1. Dubernard JM, Owen ER, Herzberg G, et al. Human hand allograft: Report on first 6 months. Lancet 1999;353:1315-20.

2. Petit F, Minns AB, Dubernard JM, Hettiaratchy S, Lee WP.

Composite tissue allotransplantation and reconstructive surgery:

First clinical applications. Ann Surg 2003;237:19-25.

3. Brenneis C, Loscher WN, Egger KE, et al. Cortical motor activation patterns following hand transplantation and replantation. J Hand Surg 2005;30:530-3.

4. Dubernard JM, Petruzzo P, Lanzetta M, et al. Functional results of the first human double-hand transplantation. Ann Surg 2003;238:128-36.

5. Francois CG, Breidenbach WC, Maldonado C, et al. Hand transplantation: Comparison and observations of the first four clinical cases. Microsurgery 2000;20:360-71.

6. Giraux P, Sirigu A, Schneider F, Dubernard JM. Functional cortical reorganization after transplantation of both hands. Nat Neurosci 2001;4:691-2.

7. Jones JW, Gruber SA, Barker JH, Breidenbach WC. Successful hand transplantation. One- year follow-up. Louisville Hand Transplant Team. N Engl J Med 2000;343:468-73.

8. Margreiter R, Brandacher G, Ninkovic M, Steurer W, Kreczy A, Schneeberger S. A double-hand transplant can be worth the effort! Transplantation 2002;74:85-90.

9. Lanzetta M, Petruzzo P, Vitale G, et al. Human hand transplantation: What have we learned? Transplant Proc 2004:36:664-8.

10. Petit F, Paraskevas A, Minns AB, Lee WP, Lantieri LA. Face transplantation: Where do we stand? Plast Reconstr Surg 2004;113:1429-33.

11. Petruzzo P, Revillard JP, Kanitakis J, et al. First human double hand transplantation: Efficacy of a conventional immunosuppressive protocol. Clin Transplant 2003;17:455-60.

12. Piza-Katzer H, Ninkovic M, Pechlaner S, Gabl M, Ninkovic M, Hussl H. Double hand transplantation: Functional outcome after 18 months. J Hand Surg 2002;27:385-90.

13. Menick FJ. Facial reconstruction with local and distant tissue: The interface of aesthetic and reconstructive surgery. Plast Reconstr Surg 1998;102:1424-33. current limitations in allotransplantation (ie, chronic rejection), circumvent the complications associated with immunosuppression and lend credence to the decision analysis model proposed (63). This would result in an increase in the number of QALYs gained with face allotransplantation, and potentially, the medical community would be more apt to accept this reconstructive procedure.

This study was not intended to reconcile the debate over the ethicality of facial transplantation $(17,22,23)$. Rather, the purpose was to assist surgeons with the decision of whether to adopt allotransplantation of the face in spite of this issue. Although this investigation did not estimate the utilities and QALYs ascribed to facial transplantation by patients with severe facial deformity, future studies are directed to that end. Nonetheless, the results of this study suggest that despite the inherent risks and uncertainties associated with CTA of the face, this procedure should be offered as a potential reconstructive option to patients with severe facial disfigurement. Whether this decision is well informed, given the lack of definitive information on the eventual outcomes of face transplantation, can only be determined with future follow-up of the CTAs performed to date, as well as the clinical course of future face transplant recipients.

This study was presented at the Canadian Society of Plastic Surgeons Annual Meeting, Quebec City, Quebec, June 13 to 17, 2006, and at the American Society for Reconstructive Microsurgery Annual Meeting, Tucson, Arizona, USA, January 14 to $16,2006$.
14. Thomas A, Obed V, Murarka A, Malhotra G. Total face and scalp replantation. Plast Reconstr Surg 1998;102:2085-7.

15. Wilhelmi BJ, Kang RH, Movassaghi K, Ganchi PA, Lee WP. First successful replantation of face and scalp with single-artery repair: Model for face and scalp transplantation. Ann Plast Surg 2003;50:535-40.

16. Lanzetta M, Petruzzo P, Margreiter R, et al. The international registry on hand and composite tissue transplantation. Transplantation 2005;79:1210-4.

17. Morris PJ, Bradley JA, Doyal L, et al. Facial transplantation: A working party report from the Royal College of Surgeons of England. Transplantation 2004;77:330-8.

18. Siemionow M, Unal S, Agaoglu G, Sari A. A cadaver study in preparation for facial allograft transplantation in humans: Part I. What are alternative sources for total facial defect coverage? Plast Recontr Surg 2006;117:864-72.

19. Siemionow M, Agaoglu G, Unal S. A cadaver study in preparation for facial allograft transplantation in humans: Part II. Mock facial transplantation. Plast Reconstr Surg 2006;113:876-85.

20. CNN Report. Woman has 'first face transplant'. December 1st 2005.

21. China Daily. China's first human face transplant successful. April 15 th, 2006

22. Clark PA. Face Transplantation: Part II - an ethical perspective. Med Sci Monit 2005;11:41-7.

23. Clark PA. Face transplantation: A medical perspective. Med Sci Monit 2005;11:1-6.

24. Cendales L, Hardy MA. Immunologic considerations in composite tissue transplantation - overview. Microsurgery 2000;20:412-9.

25. Lanzetta M, Nolli R, Borgonovo A, et al. Hand transplantation: Ethics, immunosuppression and indications. J Hand Surg 2001;26:511-6.

26. Kanitakis J, Jullien D, Petruzzo P, et al. Clinicopathologic features of graft rejection of the first human hand allograft. Transplantation 2003;76:688-93.

27. Breidenbach WC, Tobin GR, Gorantla VS, Gonzalez RN, Granger DK. A position statement in support of hand transplantation. J Hand Surg 2002;27:76-70. 
28. Edgell SE, McCabe SJ, Breidenbach WC, Neace WP, LaJoie AS, Abell TD. Different reference frames can lead to different hand transplantation decisions by patients and physicians. J Hand Surg 2001;26:196-200.

29. Drummond MF, O'Brien B, Stoddart GL, Torrance GW. Methods for the Economic Evaluation of Health Care Programmes, 2nd edn. Oxford: Oxford Medical Publications, 1997.

30. Jensen JN, Mackinnon SE. Composite tissue allotransplantation: A comprehensive review of the literature - Part III. J Reconstr Microsurg 2000;16:57-68.

31. Jensen JN, Mackinnon SE. Composite tissue allotransplantation: A comprehensive review of the literature - Part II. J Reconstr Microsurg 2000;16:141-57.

32. Jensen JN, Mackinnon SE. Composite tissue allotransplantation: A comprehensive review of the literature - Part I. J Reconstr Microsurg 2000;16:235-51.

33. Jones JW Jr, Ustuner ET, Zdichavsky M, et al. Long-term survival of an extremity composite tissue allograft with FK 506mycophenolate mofetil therapy. Surgery 1999;126:384-8.

34. Gorantla VS, Barker JH, Jones JW Jr, Prabhune K, Malsonado C, Granger DK. Immunosuppressivve agents in transplantation: Mechanisms of action and current anti-rejection strategies. Microsurgery 2000;20:420-9.

35. Jones NF, Hebebrand D, Buttemeyer R, Zhao M, Benhaim P, Rao U. Comparison of long-term immunosuppression for limb transplantation using cyclosporine, tacrolimus, and mycophenolate mofetil: Implications for clinical composite tissue transplantation. Plast Reconstr Surg 2001;107:777-84.

36. Baumeister S, Kleist C, Dohler B, Bickert B, Germann G, Opelz G. Risks of allogenic hand transplantation. Microsurgery 2004;24:98-103.

37. Pascual M, Theruvath T, Kawai T, Tolkoff-Rubin N, Cosimi AB. Strategies to improve long-term outcomes after renal transplantation. N Engl J Med 2002;346:580-90.

38. Schneeberger S, Lucchina S, Lanzetta M, et al. Cytomegalovirusrelated complications in human hand transplantation. Transplantation 2005;80:441-7.

39. U.S. Renal Data System. USRDS 2005 Annual Data Report: Atlas of End-Stage Renal Disease in the United States, National Institutes of Health. National Institute of Diabetes and Digestive and Kidney Diseases, Bethesda, Maryland, 2005.

40. Dean PG, Lund WJ, Larson TS, et al. Wound-related complications after kidney transplantation: A prospective, randomized comparison of sirolimus and tacrolimus. Transplantation 2004;77:1555-61.

41. Johnson C, Ahsan N, Gonwa T, et al. Randomized trial of tacrolimus (Prograf) in combination with azathioprine or mycophenolate mofetil versus cyclosporine (Neoral) with mycophenolate mofetil after cadaveric kidney transplantation. Transplantation 2000;69:834-41.

42. Ahsan N, Johnson C, Gonwa T, et al. Randomized trial of tacrolimus plus mycophenolate mofetil or azathioprine versus cyclosporine oral solution (modified) plus mycophenolate mofetil after cadaveric kidney transplantation: Results at 2 years. Transplantation 2001;72:245-50.

43. Gonwa T, Johnson C, Ahsan N, et al. Randomized trial of tacrolimus and mycophenolate mofetil or azathioprine versus cyclosporine and mycophenolate mofetil after cadaveric kidney transplantation: Results at three years. Transplantation 2003;75:2048-53

44. Vanrenterghem Y, van Hooff JP, Squifflet JP, et al. Minimization of immunosuppressive therapy after renal transplantation: Results of a randomized controlled trial. Am J Transplant 2005;5:87-95.

45. Miller J, Mendez R, Pirsch JD, Jensik SC. Safety and efficacy of tacrolimus in combination with mycophenolate mofetil (MMF) in cadaveric renal transplant recipients. FK506/MMF dose-ranging kidney transplant study group. Transplantation 2000;69:875-80.

46. Squifflet JP, Backman L, Claesson K, et al. Dose optimization of mycophenolate mofetil when administered with a low dose of tacrolimmus in cadaveric renal transplant recipients. Transplant 2001;72:63-9.

47. Ciancio G, Burke GW, Gaynor JJ, et al. A randomized long-term trial of tacrolimus and sirolimus versus tacrolimus and mycophenolate mofetil versus cyclosporine (Neoral) and sirolimus in renal transplantation. I. Drug interactions and rejection at one year. Transplantation 2004;77:244-51.

48. Ciancio G, Burke GW, Gaynor JJ, et al. A randomized long-term trial of tacrolimus and sirolimus versus tacrolimus and mycophenolate mofetil versus cyclosporine (Neoral) and sirolimus in renal transplantation. II. Survival, function and protocol compliance at one year. Transplantation 2004;77:252-8.

49. Ciancio G, Burke GW, et al. Daclizumab induction, tacrolimus, mycophenolate mofetil and steroids as an immunosuppression regimen for primary kidney transplant recipients. Transplantation 2002;73:1100-6.

50. Ahsan N, Holman MJ, Jarowenko MV, Razzaque MS, Yang HC. Limited dose monoclonal IL-2R antibody induction protocol primary kidney transplantation. Am J Transplant 2002;2:568-73.

51. Mendez R, Gonwa T, Yang HC, Weinstein S, Jensik S, Steinberg S, for the Prograf Study Group. A prospective, randomized trial of tacrolimus in combination with sirolimus or mycophenolate mofetil in kidney transplantation: Results at 1 year. Transplantation 2005;80:303-9.

52. Gonwa T, Mendez R, Yang HC, Weinstein S, Jensik S, Steinberg S, for the Prograf Study Group. Randomized trial of tacrolimus in combination with sirolimus or mycophenolate mofetil in kidney transplantation: Results at 6 months. Transplantation 2003;75:1213-20.

53. Miura M, Harada H, Fukuzawa N, et al. Quadruple immunosuppression with basiliximab, tacrolimus, mycophenolate mofetil and prednisone is safe and effective for renal transplantation. Clin Transplant 2005;19:54-8.

54. Goggins WC, Pascual MA, Powelson JA, et al. A prospective, randomized, clinical trial of intraoperative versus postoperative thymoglobulin in adult cadaveric renal transplant recipients. Transplantation 2003;76:798-802.

55. Urbizu JM, Amenabar JJ, Gomez-Ullate P, Zarraga S, Lampreabe I. Immunosuppression using tacrolimus/mycophenolate versus neoral/mycophenolate following kidney transplantation: A singlecenter experience. Transplant Proc 2002;34:87-8.

56. Demirbas A, Tuncer M, Yavuz A, et al. Influence of Tacrolimus plus mycophenolate mofetil regimens on acute rejection rate and diabetes mellitus development in renal transplant recipients. Transplant Proc 2004:36:175-7.

57. Ciancio G, Burke GW, Gaynor JJ, et al. A randomized trial of three renal transplant induction antibodies: Early comparison of tacrolimus, mycophenolate mofetil, and steroid dosing, and newer immune-monitoring. Transplantation 2005;80:457-65.

58. Rostaing L, Cantarovich D, Mourad G, et al. Corticosteroid-free immunosuppression with tacrolimus, mycophenolate mofetil, and daclizumab induction in renal transplantation. Transplantation 2005;79:807-14

59. Taylor DO, Edwards LB, Boucek MM, et al. Registry of the International Society for Heart and Lung Transplantation: Twentysecond Official Adult Heart Transplant Report - 2005. J Heart Lung Transplant 2005;24:945-55.

60. Dubernard JM, Owen ER, Lanzetta M, Hakim N. What is happening with hand transplants? Lancet 2001;357:1711-2.

61. Mittmann N, Trakas K, Risebrough N, Liu BA. Utility scores for chronic conditions in a community-dwelling population. Pharmacoeconomics 1999;15:369-76.

62. Gjertson DW, Cecka JM, Terasaki PI. The relative effects of FK506 and cyclosporine on short- and long-term kidney graft survival. Transplantation 1995;60:1384-8.

63. Wekerle T, Sachs DH, Sykes M. Mixed chimerism for the induction of tolerance: Potential applicability in clinical composite tissue grafting. Transplant Proc 1998;30:2708-10. 